\title{
Novel non-specific lipid-Transfer Protein (TdLTP4) isolated from Durum wheat: Antimicrobial activities to control pathogen and spoilage bacteria and Anti- Inflammatory properties in lipopolysaccharide (LPS)-stimulated RAW 264.7 macrophages
}

Anis Ben Hsouna ( $\square$ benhsounanis@yahoo.fr)

Universite de Gafsa Faculte des Sciences de Gafsa https://orcid.org/0000-0002-3837-5532

\section{Rania Ben Saad}

Centre de Biotechnologie de Sfax

\section{Wissal Dhifi}

Universite de la Manouba Institut Superieure de Biotechnologie de Sidi Thabet

\section{Marwa Khaled}

Centre de Biotechnologie de Sfax

Wissem Mnif

Universite de la Manouba Institut Superieure de Biotechnologie de Sidi Thabet

Faiçal Brini

Centre de Biotechnologie de Sfax

\section{Research}

Keywords: Biotechnology, TdLTP4, BL-21, COX-2

Posted Date: June 29th, 2020

DOI: https://doi.org/10.21203/rs.3.rs-37982/v1

License: (c) (i) This work is licensed under a Creative Commons Attribution 4.0 International License.

Read Full License 


\section{Abstract}

Background: Lipid transfer proteins (LTP) are members of the family of pathogenesis-related proteins (PR-14) that play a key role in plant defense mechanisms.

Methods: In this study, a novel gene TdLTP4 encoding an antifungal protein from wheat ( $c v$. Om Rabiaa) was subcloned, overexpressed in Escherichia coli BL-21 (DE3) and enriched using ammonium sulfate fractionation. The TdLTP4 fusion protein was then tested against a panel of pathogens, food-borne and spoilage bacteria and fungi in order to evaluate the antimicrobial properties. Our protein was applied to $0.5 \mu \mathrm{g} / \mathrm{mL}$ LPS-induced RAW 264.7 macrophages in vitro at different concentrations $(5,10,20,50$ and $100 \mu \mathrm{g} / \mathrm{ml}$ ). Levels of nitric oxide (NO), pro-inflammatory cytokines interleukin (IL)-1 $\beta$ (IL-1 $\beta$ ), interleukin (IL)-6 (IL-6), tumor necrosis factor (TNF- $\alpha$ ) and anti-inflammatory cytokine IL-10 in the supernatant fraction were measured using enzyme-linked immunosorbent assay (ELISA). Expression of cyclooxygenase-2 (COX-2) and inducible nitric oxide synthase (iNOS) were detected via Western blot.

Results: The inhibition zones and minimal inhibitory concentration (MIC) values of bacterial strains were in the range of $14-26 \mathrm{~mm}$ and $62.5-250 \mu \mathrm{g} / \mathrm{mL}$, respectively. Moreover, a remarkable activity against several fungal strains was revealed. TdLTP4 $(5-100 \mu \mathrm{g} / \mathrm{mL})$ decreased the production of NO $\left(\mathrm{IC}_{50}=4.32\right.$ $\mu \mathrm{g} / \mathrm{mL}), I L-6\left(I C_{50}=11.52 \mu \mathrm{g} / \mathrm{mL}\right), I L-1 \beta\left(I C_{50}=7.87 \mu \mathrm{g} / \mathrm{mL}\right)$ and TNF-a $\left(I_{50}=8.66 \mu \mathrm{g} / \mathrm{mL}\right)$ by lipopolysaccharide (LPS)-stimulated RAW 264.7 macrophages. Our protein could modulate the macrophages inflammatory mode by causing reduction in iNOS and $\mathrm{COX}_{2}$.

Conclusion: According to these findings, LTP fusion protein could be used as natural anti-inflammatory and antimicrobial agent in food preservation and human health.

\section{Background}

Food borne diseases caused by microorganisms are major dilemma in the third world and developing countries, and even in developed nations (Tondo et al., 2015). The consumption of foods contaminated with some microorganisms is considered as a serious human health risk. The subsistence and growth of microorganisms in foods may lead to spoilage, toxins secretion with quality deterioration of food products as a global consequence (Casewell et al., 2003). To overcome these problems, a wide range of synthetic antimicrobial agents such as the sodium or calcium benzoate and methicillin have been used in food preservation in human infectious diseases respectively (Mathur and Singh, 2005). Thus, the discovery of new antimicrobial compounds has become a major challenge of researchers and pharmaceutical industries. Therefore, there is great interest in finding new and safe antibacterial compounds from natural sources .

Although inflammation is a physiological imperative response of the immune system to pathogens or tissue destruction, it may, under specific conditions, evolve into a chronically pro-inflammatory state. This pro-inflammatory state constitutes a serious a risk factor for several diseases even in the absence of immediate clinical symptoms (Jianget al., 2017). Macrophages play key roles in the early stages of an 
inflammatory response by instating favourable conditions for chronic inflammation, which eventually can lead to tissue damage (Abarikwu, 2014). LPS, a component of the Gram-negative bacteria cell wall, has been often used in inflammatory response as macrophages activator (Shi et al., 2014). LPS-stimulated macrophages activate several intracellular signaling pathways leading to several molecules such as NO, COX-2 derived eicosanoids, signalling peptides like interleukin (IL)-1 $\beta$ and IL-6, and tumour necrosis factor (TNF)- $\alpha$ and the chemokine monocyte chemotactic protein-1 (MCP-1) released by activated macrophages (Nguyen et al., 2015). Chronic inflammation is the main pathogenic cause of many autoimmune diseases. The treatment of such diseases is based on long or life-long administration of antiinflammatory drugs. Because of their side effects, scientists are looking for a safer and more efficient alternative to conventional anti-inflammatory drugs such as plant substances.

The use of chemical additives has been arisen in recent years. In the next decades, the development of alternative drugs and/or natural molecules would be of high interest among researchers. Recently, peptide derived from plants have been recognized as safe, highly stable and effective natural antioxidants in pharmaceutical and food fields due to their nontoxicity and insignificant side-effects (Mir, et al 2017).

Plant nonspecific lipid transfer proteins (ns-LTP) are abundant and ubiquitous, small, soluble, basic cystine-rich proteins exhibiting four a-helices which are stabilized by four intramolecular disulphide bonds (Edstam et al. 2011). They are particularly abundant in higher plants. The structures of plant ns-LTP are characterized by an eight-cysteine residue conserved motif, linked by four disulfide bonds, and an internal hydrophobic cavity, which comprises the lipid-binding site. This structure confers a great stability to these proteins and increases the ability to bind and/or carry hydrophobic molecules (Perrocheau et al. 2006).

There are two families of ns-LTP, ns-LTP1 and ns-LTP2, with molecular masses of 10 and $7 \mathrm{kDa}$ (Gasteiger et al., 2005) and play key roles in vital processes of plant cytology, such as the stabilization of membranes, cell wall organization, and signal transduction. nsLTPs are reputed for their role in resistance to biotic and abiotic stresses as well as in plant growth and development (DeBono et al., 2009;

Panikashvili et al., 2010). Their extracellular distribution in the exposed surfaces in vascular tissue systems, high abundance and expression in response to infection by pathogens suggest that they are active plant-defense proteins (Molina and Garcia-Olmedo, 1993). In addition to being a main source of carbohydrates, Cereals are also rich in proteins and bioactive peptides with nutraceutical activities and among them ns-LTP (Sánchez and Vázquez, 2017 ; Chakrabarti et al. 2014).

To our knowledge, no reports are available concerning wheat ns-LTP antimicrobial and anti-inflammatory activities. This work is the first investigation dealing with ns-LTP potential to reduce inflammation effects in LPS stimulated RAW 264.7 murine macrophages in vitro and their antimicrobial activities against different microorganisms, including Gram-positive and negative bacteria and fungi using well diffusion agar and broth microdilution methods of ns-LTP.

\section{Materials And Methods}




\section{Expression and purification of the recombinant TdLTP4 protein in E. coli}

TdLTP4 protein from Triticum turgidum L. subsp. Durum Desf has been characterized by Safi et al. (2015). TdLTP4 open reading frame (ORF) was amplified with PfuTurbo DNA polymerase (Stratagene, La Jolla, CA) using primers corresponding to the $5^{\prime}$ and $3^{\prime}$ ends with $E c o R /$ restriction sites added. These oligonucleotide primers were TdLTP4-F: 5'-TTAGAATTCATGGCCCGTTCTGCTCTTG -3' and TdLTP4-R: 5'TTAGAATTCTCAGCGAATCTTAGAGCA -3'. The TdLTP4 ORF was cloned into the EcoR/ site of E. coli expression vector pGEX-4T-1 resulting in fusion with GST, and was transformed into E. coli BL21. Cultures of E. coli cells carrying pGEX-4T-1:GST-TdLTP4 or vector control (pGEX-4T-1) were grown at $30^{\circ} \mathrm{C}$ in LB medium containing $100 \mu \mathrm{g} / \mathrm{mL}$ ampicillin to an A600 $=0.6-0.8$, and induced with $1 \mathrm{mM}$ IPTG (isopropyl $\beta$-D-thiogalactopyranosid) overnight at $30^{\circ} \mathrm{C}$. The next day, cells were pelleted and suspended in cold binding buffer (20 mM tris, pH8, $100 \mathrm{mM} \mathrm{NaCl}, 1 \mathrm{mM}$ EDTA, 0.5\% NP40) in the presence of protease inhibitors. The cells were then subsequently lysed by sonication on ice. The supernatant was separated by centrifugation and used for purification of TdLTP4 under native conditions using a GlutathioneSepharose column (GE Healthcare). The column was washed with binding buffer containing $0.7 \mathrm{M} \mathrm{NaCl}$ and TdLTP4 step-eluted after digestion with thrombin overnight at $16^{\circ} \mathrm{C}$. Protein quantification was performed using the Bradford method. Bovine serum albumin was used as a standard. The purity and the correct size of the recombinant proteins were verified by SDS-PAGE.

\section{Antimicrobial screening}

\section{Microorganisms and growth conditions}

Bacteria and fungi were obtained from international culture collections (ATCC) and the local culture collection of the Centre of Biotechnology of Sfax, Tunisia. They included Gram+ positive bacteria: Bacillus subtilis ATCC 6633, Bacillus cereus ATCC 14579, Staphylococcus aureus ATCC 25923 , Staphylococcus epidermis ATCC 12228, Enterococcus faecalis ATCC 29212, Listeria monocytogenes ATCC 19117 and Gram-negative bacteria: Salmonella enterica ATCC 43972, Escherichia coli ATCC 25922, Pseudomonas aeruginosa ATCC 9027.

The following fungal strains were also tested: Aspergillus niger (CTM 10099), Aspergillus flavus (food isolate), Aspergillus nidulans (food isolate), Aspergillus fumigatus (food isolate), Fusarium graminearum (ISPAVE 271), Fusarium oxysporum (CTM10402), Fusarium culmorum (ISPAVE 21w) and Alternaria alternata (CTM 10230).

Bacteria were cultivated in Muller-Hinton agar (MH) at $37^{\circ} \mathrm{C}$ except for Bacillus species which were incubated at $30^{\circ} \mathrm{C}$. Fungi were cultured on Potatoes Dextrose agar (PDA) medium and incubated at 28 ${ }^{\circ} \mathrm{C}$. Working cultures were prepared by inoculating a loopful of each test bacteria in $3 \mathrm{ml}$ of Muller-Hinton broth $(\mathrm{MH})(\mathrm{Oxoid} \mathrm{Ltd}, \mathrm{UK})$ and were incubated at $37^{\circ} \mathrm{C}$ for $12 \mathrm{~h}$. The cell concentrations were adjusted to approximately $10^{6} \mathrm{CFU} / \mathrm{ml}$. Fungal spore suspensions were collected by gently scraping with a loop and suspended in $10 \mathrm{ml}$ Potato Dextrose Broth (PDB). This suspension was mixed vigorously by vortexing for 
$15-20 \mathrm{~min}$. The spore suspension stock was diluted to obtain a concentration of $10^{6} \mathrm{spores} / \mathrm{mL}$ (measured by Malassez blade).

The determination of the inhibition zone diameter (IZ), minimum inhibitory concentration (MIC), minimum bactericidal concentration (MBC), and minimum fungicidal concentration (MFC) were based on the same protocol as described by Ben Hsouna et al. $(2011$; 2017 ; 2019 ;2020).

\section{Cell culture and MTT assay}

The cells were cultured in DMEM medium supplemented with 10\% heat-inactivated FBS, $1 \%$ streptomycin/penicillin at $37{ }^{\circ} \mathrm{C}$ in a humidified atmosphere of $5 \% \mathrm{CO}$. The cells were treated with TdLTP4 at different concentrations and then stimulated with $0.5 \mu \mathrm{g} / \mathrm{mL}$ LPS for $18 \mathrm{~h}$ (Ben Hsouna et al., 2018; 2019).

Cell viability assay

The cells were seeded in a 96-well plate and treated with various concentrations of TdLTP4 for $24 \mathrm{~h}$. The cell viability was measured by an MTT assay according to our previously described method (Tursun et al., 2016 ; Ben Hsouna et al., 2019).

Measurement of NO production

RAW 264.7 cells $(2 \times 105$ cells/well) were pre-incubated for $1 \mathrm{~h}$ with various concentrations of TdLTP4 and stimulated with $L P S(0.5 \mu \mathrm{g} / \mathrm{mL})$ at $37^{\circ} \mathrm{C}$ for $18 \mathrm{~h}$ in medium. NO levels were determined by measuring nitrite levels in the culture media using Griess reagent assay according to our previously described method (Tursun et al., 2016; Ben Hsouna et al., 2019, 2018).

Measurement of IL-6, IL-1 $\beta$, TNF- $\alpha$ and IL-10 levels

RAW264.7 cells $\left(2 \times 10^{5}\right.$ cells/well) were pretreated with different concentrations of TdLTP4 for $1 \mathrm{~h}$ and then stimulated with LPS $(0.5 \mu \mathrm{g} / \mathrm{mL})$ for $18 \mathrm{~h}$. The concentration of IL-6, TNF-a, IL-10 and IL-1 $\beta$ were assayed using the ELISA kits according to the manufacturer's instructions (Ben Hsouna et al., 2018; 2019).

Western blot analysis

Protein extracts were separated by SDS-PAGE and transferred to polyvinylidene difluoride (PVDF) membranes. Protein concentrations were determined using the BCA assay. Whole cell extracts, cytosolic and nuclear proteins were extracted respectively and the western blot analysis were as described previously (Tursun et al., 2016). The membranes were further incubated with the secondary antibody for 4 $h$ at room temperature and detected using an enhanced chemiluminescence reagent. The membranes were washed three times and the immunoreactive proteins were detected with an enhanced chemiluminescence system (GE Healthcare, Little Chalfont, Buckinghanshire, UK). 


\section{Statistical analysis}

The experimental results concerning this study were expressed as a mean \pm standard deviation (SD) of the 3 parallel measurements. The results were analyzed by One-Way Analysis of Variance (ANOVA) followed by Tukey test for multiple comparisons using SPSS for Windows (version. 12) or ANOVA-onranks with Dunn's correction. Differences were considered significant at $P<0.05$.

\section{Results}

\section{Production and purification of the recombinant TdLTP4protein in E. coli}

The TdLTP4 nucleotide sequence was obtained using gene-specific primers. The ORF of TdLTP4 was cloned in-frame with the $3^{\prime}$ end of the coding sequence of GST using PGEX-4T-1 expression vector. After IPTG induction, the resulting recombinant GST: TdLTP4 protein accumulated to high amounts in the $E$. coli cells BL21 (Fig. 1). The calculated molecular weight of the recombinant TdLTP4 was estimated to about $12 \mathrm{kDa}$, while the molecular weight of GST was $26 \mathrm{kDa}$, identical size revealed by SDS-PAGE. Thus, the fusion protein was approximately $38 \mathrm{kDa}$ (Fig. 1).

\section{Antimicrobial activities}

The antibacterial activity of TdLTP4 was evaluated against Gram-positive (B. subtilis, B. cereus, $S$. aureus, S. epidermis, E. faecalis and L. monocytogenes ATCC 19117) and Gram-negative (E. coli, P. aeruginosa and $S$. enterica) bacteria. The antibacterial activity was assessed by evaluating the inhibition zone (IZ) and the determination of MIC and MBC values (Table 1).

The results summarized in Table 1 revealed that TdLTP4 protein displayed a broad antimicrobial spectrum and exerted a significant antibacterial effect against both tested Gram-positive and Gramnegative bacteria. It is worth noting that the most susceptible bacteria for the purified protein were $S$. aureus and $L$. monocytogenes with MIC values of $62.5 \mu \mathrm{g} / \mathrm{mL}$. The highest MIC value characterized $S$. enterica and $P$. aeruginosa $(250 \mu \mathrm{g} / \mathrm{mL})$.

Table 2 summarized the results relative to the antifungal screening. The TdLTP4 purified protein displayed antifungal activity against $A$. niger, F. solani, F. oxysporium and $F$. granularium with MIC values of 125 , and $62.5 \mu \mathrm{g} / \mathrm{ml}$, respectively. Besides, the TdLTP4 exhibited an antifungal activity against Aspergillus species such as $A$. niger, $A$. flavus, $A$. fumigatus and $A$. nidulans which are responsible for spoilage of many foods and feeds. The inhibition zone and the MIC values of the tested protein against Aspergillus species were of $18-20 \mathrm{~mm}$ and at $125-500 \mu \mathrm{g} / \mathrm{mL}$, respectively.

Effect of TdLTP4 protein on RAW 264.7 cell viability

RAW264.7 cells were initially seeded in microplates followed by different concentrations of TdLTP4 protein. Treating RAW 264.7 cells with TdLTP4 protein $(0-100 \mu \mathrm{g} / \mathrm{mL})$ did not affect their viability (Fig. 2). 
Therefore, we used the TdLTP4 protein at concentrations of 5, 10,20, 50 and $100 \mu \mathrm{g} / \mathrm{mL}$ in subsequent experiments.

Effect of TdLTP4 protein on NO production, iNOS and COX-2 expression

The amounts of nitrite, a stable metabolite of NO, were determined via the Griess reaction. As presented in Figure, in unstimulated RAW 264.7 cells, NO production were almost undetectable. Upon LPS treatment, nitrite production increased markedly in the medium. However, TdLTP4 protein suppressed NO production in the LPS-treated cells in a dose-dependent manner.

We then tested the effect of TdLTP4 protein on iNOS and COX-2 expressions. Western blot analysis demonstrated that unstimulated RAW264.7 cells did not express iNOS and COX-2 proteins whereas LPS treatment induced iNOS and COX-2 expressions. Western blotting with TdLTP4 protein of anti-iNOS and COX-2 antibodies showed lower iNOS and COX-2 protein levels, indicating that TdLTP4 protein could regulate inflammatory effects through inhibiting the iNOS and COX-2 pathway (Fig. 4).

\section{TdLTP4Effects on LPS-induced inflammatory cytokines}

Proinflammatory cytokines, such as $T N F-a, I L-1 \beta$ and IL-6 and anti-inflammatory cytokine IL-10 play important roles in the inflammatory process. The treatment of RAW 264.7 cells with LPS alone resulted in an increased release of the fore-mentioned cytokines compared with that in non-activated controls (Fig. $5)$.

The increased levels of TNF- $a$, (Figure 5 A), IL-1 $\beta$ (Fig. 5C), and IL-6 (Fig. 5B) in RAW 264.7 cells by LPS stimulation remarkably decreased in a dose-dependent manner after cells exposure to TdLTP4 $(p<0.05)$. By contrast, the antiinflammatory cytokine IL-10 level significantly increased in a dose-dependent manner after cells exposure to the purified protein ( $p<0.05$; Fig. $5 \mathrm{D}$ ).

\section{Discussion}

Since controlling bacterial infections is a serious problem as a result of the growing bacterial resistance against a large spectrum of commercial antibiotics, the research of new natural molecules without side effects and acting as antibacterial agents has recently expanded (Gardam, 2000). According to, LTP various members are characterized by antibacterial, antifungal, antiviral, and antiproliferative activities. They are also able to inhibit some enzymes (Carvalho et Gomes, 2007). In our study, the results of the antibacterial screening showed that TdLTP4 protein tested have potential antibacterial activity against a panel of human and foodborn pathogenic bacteria such as Listeria monocytogenes, Salmonella enterica, Staphylococcus aureus, Escherichia coli and Bacillus subtilis,. TdLTP4 exhibited a promising antibacterial effect by inhibition zones and MIC values for against the tested bacteria. Gram-negative bacteria are generally less susceptible to protein extract from plants than the Gram-positive bacteria, since they have an outer membrane which plays the role of a barrier to the biomolecules (Cox et al., 2001). These results are in agreement with the findings of Ben Hsouna et al., (2020) who reported that the Annexin 12 protein 
extracted from Triticum durum exhibited the highest inhibitory effect against Gram-negative bacteria. Comparing MIC and MBC, bioactive components from natural products can be classified into bacteriostatic $(\mathrm{MIC}<\mathrm{MBC})$ and bactericide agent $(\mathrm{MIC}=\mathrm{MBC})$. According to these parameters, the purified peptide from $T$. turgidum can be considered as a bactericide agent against $L$. monocytogenes, $B$. subtilis, $B$. cereus and $P$. aeruginosa, however, a bacteriostatic agent against all other tested bacteria. The mechanisms involved in the antibacterial activity of TdLTP4 are worthy of further investigations but it suggested that they might act as barriers inhibiting bacterial growth by stopping the import of nutriments (Ren et al., 2014).

Contamination by Aspergillus, Fusarium and Alternaria species and with their respective mycotoxins is considered as a challenge for the pharmaceutical and food industries. TdLTP4are widely claimed to have a broad-spectrum antifungal activity and are considered as a main source for the search of lead compounds. The present study reports the capacity of the TdLTP4 extracted from Triticum Turgidum to control Aspergillus strains, Fusarium graminearum and Alternaria alternata strains. Therefore, TdLTP4 could be considered as one of the sources of natural antibiotics against opportunistic pathogens and could be used as food anti-poisoning agents.

It has been reported that pepper and coffee LTPs from pepper and coffee are active against human pathogenic fungal strains from the Candida genus (Zottich et al., 2011). Moreover, it is important to mention that the antimicrobial activity of most plant LTPs is specific and targeted against particular microorganisms. Like plant defensins, LTPs can have a synergic effect with thionins (Molina et al., 1993). Interestingly, they are exempt from toxic effects on plant cells and mammalian cells, including fibroblasts and red blood cells (Regente et al., 2005).

Plant LTPs possessy fungistatic andfungicidal activities. Moreover, they are able to induce permeabilization of the model membranes and cell membranes of pathogenic fungi (Regente et al., 2005).

Overexpression of a barley type 2 ns-LTP in transgenic tobacco and Arabidopsis has been shown to enhance resistance to Pseudomonas syringae pvs. Tabaci and tomato (Molina and García-Olmedo, 1997). DIR1, an ns- LTP from Arabidopsis, was reported to be involved in long distance signaling, possibly by binding a lipid molecule during systemic acquired resistance (Maldonado et al., 2002). LTPs can inhibit the growth of fungal pathogens in vitro. Interestingly, they are capable of synergistically enhancing the antimicrobial properties of other antimicrobial peptides such as defensins and thionins (Marion et al., 2004). The relative activities of different plant LTPs against pathogens vary, suggesting that they have various selectivity degrees. Van Loon et al. (1999) demonstrated the antifungal activity against Trichoderma viridae and Rhizoctonia solani using purified protein from pearl millet seeds which had sequence homology with LTPs of cotton, wheat and barley. An antifungal protein purified to homogeneity from sunflower (Helianthus annuus L.) seeds (Ha-AP10) exerted a fungistatic effect that inhibits germination of Fusarium solani f. sp. eumartii spores (Regente and De la Canal, 2005). 
All LTPs are basic proteins ( $\mathrm{pl} \sim 9-10)$. The vast majority of LTPs contain eight conserved cysteine residues (Cl...CII...CIIICIV...CVXCVI...CVII...CVIII...) forming four disulfide bonds that stabilize their structure and, thereby, underlie the resistance of LTPs to high temperatures and proteolytic enzymes. Some proteins from this class maintain their native conformation as well as their biological activity even after incubation at a temperature of about $100^{\circ} \mathrm{C}$ (Perrocheau et al. 2006). According to Sun et al. (2008), there is no correlation between the antimicrobial activity of plant LTPs and their ability to interact with lipids. For example, this correlation was not found in eight wheat LTP isoforms capable of inhibiting the growth of pathogenic microorganisms. A similar finding was reported in the cases of onion Ace-AMP1 (Cammue et al., 1995) and a mutant rice LTP isoform (Guo et al., 2013). It was also shown that this class of proteins may possess antimicrobial activity but not bind lipid molecules and vice versa. Plant LTPs have not only fungistatic, but also fungicidal activity and, like other AMPs, are able to induce permeabilization of the model membranes (Regente et al., 2005) and cell membranes of pathogenic fungi (Sun et al., 2008; Regente et al., 2005). For example, LTPs from onion (Tassin et al., 1998), sunflower (Sun et al., 2008), and, to a lesser extent, barley (Caaveiro et al., 1997) are able to induce permeabilization of liposomes consisting of anionic phospholipids only or a mixture of anionic and neutral phospholipids, causing fluorescent dye leakage from liposomes.

In the present study, we also investigated anti-inflammatory effects of TdLTP4 on LPS-stimulated RAW 264.7 macrophage cells. To our knowledge, this study is the first to assess the potential for ns-LTP to reduce inflammatory effects in LPS stimulated RAW 264.7 murine macrophages in vitro.

Inflammation is a bodily response to harmful stimuli such as injury and infection (Choi et al., 2014). Various inflammatory models allow evaluation of test compounds and provide further understanding about the inflammatory process. In many studies, anti-inflammatory compounds have been investigated for their potential inhibitory effects in vitro using LPS-stimulated RAW 264.7 macrophages. LPS, a component of the outer membrane of gram-negative bacteria, can activate murine macrophages thus inducing an over secretion of various inflammatory and toxicity-mediating molecules, such as TNF-a, IL-6, eicosanoids, and NO (Yang et al., 2009). At the $5-100 \mu \mathrm{g} / \mathrm{mL}$ concentrations, TdLTP4 did not show any cytotoxic effects on the cells. NO is the free radical product of the oxidative deamination of L-arginine, which is catalyzed by NOS. At low concentrations, NO plays a role as a signaling molecule in various physiological processes. During inflammation, the inducible isoform of the enzyme (iNOS or NOS2) is upregulated and this produces large amounts of NO, acting as a key mediator in several inflammatory disorders (Bogdan, 2001). Under these conditions, the expression of iNOS mediator in several inflammatory disorders (Bogdan, 2001). Our results showed that the TdLTP4 protein could reduce NO levels in a concentration-dependent way.

In our case, LPS-activated macrophages increased the protein expression levels of COX-2 and iNOS compared with those in the untreated control group. By contrast, TdLTP4 treatment was down-regulated the expression of these LPS-stimulated proteins in a concentration-dependent manner. Similar facts have been reported by Ko et al. (2017) noticed an increased expression levels of iNOS and COX-2 in the LPS- 
stimulated cells by comparison with the untreated control. These results are consistent with the inhibitory effects of TdLTP4 on the production of NO and PGE2.

To evaluate the anti-inflammatory mechanism mediated by TdLTP4, we investigated the effects of this protein on LPS- induced cytokine production, including proinflammatory cytokines, such as IL-1 $\beta$ and IL-6, as well as TNF- $\alpha$ and the anti-inflammatory cytokine IL-10, which are regarded as crucial antiinflammatory targets (Haddad et al., 203; Pettus et al., 2003).

Proinflammatory cytokines, such as TNF- $-\mathrm{I}, \mathrm{IL}-1 \beta$, and IL-6, are produced primarily by activated monocytes or macrophages. According to our results, the treatment of RAW 264.7 cells with LPS alone resulted in a significant increase in proinflammatory cytokine production compared with that in the control group $(\mathrm{p}<$ 0.001). By contrast, TdLTP4 significantly reduced these cytokine levels $(p<0.001)$. IL-10 is generally considered as an anti-inflammatory and immunosuppressive cytokine. Its inhibitory effect on the production of inflammatory cytokines, including TNF-a, IL-1 $\beta$, and IL- 6 , has been reported in numerous studies (Raychaudhuri et al 2000). In the current study, TdLTP4 significantly increased the levels of antiinflammatory cytokine IL-10. These results are in concordance with those of Rayaprolu et al. (2017) who reported that IL-6 and TNF-a production was considerably increased in LPS- stimulated RAW 264.7 cells but significantly inhibited by Hazelnut protein-derived peptide LDAPGHR in a dose-dependent manner .

Sangtanoo et al. (2020) reported that Peanut worm (Sipunculus nudus Linn.) LTP reduced the expression of proinflammatory cytokine genes iNOS, IL-6, TNF-a, and COX-2 in RAW 264.7 macrophages. They are proposed as novel anti-inflammatory candidates. Therefore, in our case, the regulation of cytokines may reflect one of the mechanisms underlying the anti-inflammatory effect of TdLTP4 protein.

LTPs from Chinese daffodil (Narcissus tazetta) and cole seed (Brassica campestris) were reported to have antiviral activity and the ability to inhibit the proliferation of human tumor cells. Invitro experiments, N. tazetta LTP, designated as NTP, significantly inhibited plaque formation of the respiratory syncytial virus (RSV), the cytopathic effect of the influenza A virus (H1N1), and the proliferation of the human acute promyelocytic leukemia cell (HL-60). B. campestris LTP inhibit the activity of HIV-1 reverse transcriptase and the proliferation of hepatoma HepG2 and breast cancer MCF7 cells. To date, the mechanism of LTP anti-tumor activity has not been determined (Ooi et al. 2008; Lin et al. 2007).

\section{Conclusion}

Plants dietary and health values have gained an increasing interest during the last decade. Hence, peptides derived from plants were more recommended in several oxidative stress-related diseases as cancer or microbial contamination due to the beneficial effects and the several bioactivities of the natural products. In this study, we show that TdLTP4 protein exhibit a broad spectrum of biological activities such as antibacterial, antifungal and anti-inflammatory activities. Furthermore, our results showed the potential of TdLTP4 protein from Triticum turgidumas a source for natural health products or natural food preservatives due to its high antibacterial and antifungal activities against a panel of food pathogenic bacteria and fungus. 
Moreover, TdLTP4 protein exerted potent anti-inflammatory effects through down-regulating expression of multiple inflammatory cytokines and related mediators including $T N F-a, I L-1 \beta, I L-6$, anti-inflammatory cytokine IL-10, NO, iNOS, and COX-2 in the LPS-induced macrophages. These findings may indicate the potential utility of the TdLTP4 protein as an ingredient of functional foods. However, in vivo research focusing on the anti-inflammatory effect and structure-activity is needed before the use/application of this LTP as an ingredient of functional foods. Moreover, further investigation toelucidate the structureactivity relationship of TdLTP4 protein and its antimicrobial and anti-inflammatory activitiespossible molecular mechanism is required.

\section{Declarations}

\section{Acknowledgment}

This work was supported by grants from Ministry of Higher Education and Scientific Research, Tunisia.

\section{Funding}

Not applicable.

\section{Authors' contributions}

$A B H, R B S, W D, M K, W M$ and FB designed and wrote the paper. All authors have read and approved the final manuscript.

\section{Competing interests}

The authors declare that they have no competing interests.

\section{Consent for publication}

Not applicable.

\section{Ethics approval and consent to participate}

Not applicable.

\section{References}

Abarikwu SO. Kolaviron, a natural flavonoid from the seeds of Garcinia kola, reduces LPS-induced inflammation in macrophages by combined inhibition of IL- 6 secretion, and inflammatory transcription factors, ERK1/2, NF-KB, p38, Akt, p-c-JUN and JNK. Biochimica et Biophysica Acta (BBA) - General Subjects. 2014; 1840(7), 2373-81. 
Ben Hsouna A, Ben Halima N, Smaoui S, Hamdi N. Citrus lemon essential oil: chemical composition, antioxidant and antimicrobial activities with its preservative effect against Listeria monocytogenes inoculated in minced beef meat. Lipids Health Dis. 2017; 16(1): 146.

Ben Hsouna A, Ben Saad R, Trabelsi I, Ben Romdhane W, Brini F, Ben Salah R. A novel Triticum durum Annexin 12 protein: Expression, purification and Biological activities against Listeria monocytogenes growth in meat under refrigeration. Microbial pathogensis. 2020; 143:104143.

Ben Hsouna A, Ben Saad R, Zouari N, Ben Romdhane W, Brini F, Ben Salah R. Stress associated protein from Lobularia maritima: Heterologous expression, antioxidant and antimicrobial activities with its preservative effect against Listeria monocytogenes inoculated in beef meat. Int J Biol Macromol. 2019; 132:888-896.

Ben Hsouna A, Dhibi S, Dhifi W, Ben Saad R, Brini F, Hfaidh N, Mnif W. Essential oil from halophyte Lobularia maritima : protective effects against $\mathrm{CCl} 4$-induced hepatic oxidative damage in rats and inhibition of the production of proinflammatory gene expression by lipopolysaccharide-stimulated RAW 264.7 macrophages. RSC Adv. 2019; 9:36758-70.

Ben Hsouna A, Gargouri M, Dhifi W, Ben Saad R, Sayahi N, Mnif W, Saib W. Potential anti-inflammatory and antioxidant effects of Citrus aurantium essential oil against carbon tetrachloridemediated hepatotoxicity: A biochemical, molecular and histopathological changes in adult rats. Environmental Toxicology. 2018;1-13. https://doi.org/10.1002/tox.22693

Ben Hsouna A, Trigui M, Mansour RB, Jarraya RM, Damak M, Jaoua S. Chemical composition, cytotoxicity effect and antimicrobial activity of Ceratonia siliqua essential oil with preservative effects against Listeria inoculated in minced beef meat. Int J Food Microbiol. 2011; 148(1): 66-72.

Bogdan, C. Nitric oxide and the immune response. Nat. Immunol. 2001; 2:907-916.

Bradford MM. A rapid and sensitive method for the quantitation of microgram quantities of protein utilizing the principle of protein-dye binding. Anal Biochem. 1976; 72(1-2): 248-54.

Caaveiro JMM, Molina A, González-Mañas JM, Rodríguez- Palenzuela P, García-Olmedo F, Goñi FM. Differential effects of five types of antipathogenic plant peptides on model membranes. FEBS Letters. $1997 ; 410: 338-42$.

Cammue BA, Thevissen K, Hendriks M, Eggermont K, Goderis I, Proost P, van Damme J, Osborn RW, Guerbette F, Kader J, Broekaert WP. A potent antimicrobial protein from onion seeds showing sequence homology to plant lipid transfer proteins. Plant Physiol. 1995; 109:445-55.

Carvalho AO, Gomes VM. Role of plant lipid transfer proteins in plant cell physiology - a concise review. Peptides. 2007; 28:1144-53. 
Casewell M, Friis C, Marco E, McMullin P, Phillips I. The European ban on growth-promoting antibiotics and emerging consequences for human and animal health, Journal of Antimicrobial Chemotherapy. 2003; 52: 159-161.

Chakrabarti S. Jahandideh F. Wu J. Food-derived bioactive peptides on inflammation and oxidative stress. Biomed. Res. Int. 2014; 608979.

Choi YH, Kim GY, Lee HH. Anti-inflammatory Effects of Cordycepin in Lipopolysaccharide-Stimulated RAW 264.7 Macrophages Through Toll-like Receptor 4-mediated Suppression of Mitogen-Activated Protein Kinases and NF-KB Signaling Pathways. Drug Des Devel Ther. 2014; 16;8:1941-53.

Cox SD, Mann CM, Markham JL, Bell HC, Gustafson JE, Warmington JR, Wyllie SG. The mode of antimicrobial action of the essential oil of Melaleuca alternifolia (tea tree oil). J. Appl. Microbiol. 2001; 88(1): $170-5$.

DeBono A, Yeats TH, Rose JK, Bird D, Jetter R, Kunst L, Samuels L. Arabidopsis LTPG is a glycosylphosphatidylinosotol-anchored lipid transfer protein required for export of lipids to the plant surface. Plant Cell. 2009; 21:1230-8.

Edstam MM, Viitanen L, Salminen TA, Edqvist J. Evolutionary history of the non-specific lipid transfer proteins. Mol. Proteins. 2011;4 (6): 947-64.

Gardam MA. Is methicillin-resistant Staphylococcus aureus an emerging community pathogen-A review of the literature. Can J Infect Dis. 2000; 11(4): 202-11.

Gasteiger E, Hoogland C, Gattiker A, Duvaud S, Wilkins MR, Appel RD, Bairoch A. In:Walker, John M. (Ed.), The Proteomics Protocols Handbook. Humana Press. 2005; pp. 571-607.

Guo C, Ge X, Ma H. The Rice OsDIL Gene Plays a Role in Drought Tolerance at Vegetative and Reproductive Stages. Plant Mol Biol. 2013; 82(3):239-53.

Haddad JJ, Saade NE, Safieh-Garabedian B. Interleukin-10 and the Regulation of Mitogen-Activated Protein Kinases: Are These Signalling Modules Targets for the Anti-Inflammatory Action of This Cytokine? Cell Signal. 2003; 15(3):255-67.

Jiang F, Guan H, Liu D, Wu X, Fan M, Han J. Flavonoids from sea buckthorn inhibit the lipopolysaccharideinduced inflammatory response in RAW264. 7 macrophages through the MAPK and NF-KB pathways. Food \& Function. 2017; 8(3): 1313-22.

Ko YJ, Ahn G, Ham YM, Song SM, Ko EY, Cho SH, Yoon WJ, Kim KN. Anti-inflammatory Effect and Mechanism of Action of Lindera erythrocarpa Essential Oil in Lipopolysaccharide-Stimulated RAW264.7 Cells. EXCLI J. 2017; 29;16:1103-13. 
Lin P, Xia L, Wong JH, Ng TB, Ye X, Wang S, Shi X. Lipid Transfer Proteins From Brassica Campestris and Mung Bean Surpass Mung Bean Chitinase in Exploitability. J Pept Sci. 2007; 13(10):642-8.

Maldonado AM, Doerner P, Dixon RA, Lamb CJ, Cameron RK. A putative lipid transfer protein involved in systemic resistance signalling in Arabidopsis. Nature. 2002; 419: 399-403.

Marion D, Douliez JP, Gautier MF, Elmorjani K. Plant lipid transfer proteins: relationships between allergenicity and structural, biological and technological properties. In: Mills, E.N.C., Shewry, P.R. (Eds.), Plant Food Allergens. Blackwell Science, Oxford. 2004; pp. 57-69.

Mathur S, Singh R. Antibiotic resistance in food lactic acid bacteria, a review, International Journal of Food Microbiology. 2005;105 (3): 281-95.

Mir SA, Masoodi FA, Raja J. Influence of natural antioxidants on microbial load, lipid oxidatioand sensorial quality of rista-A traditional meat product of India. Food Bioscience. 2017; 20: 79-87.

Molina A, Garcia-Olmedo F. Developmental and pathogen-induced expression of three barley genes encoding lipid transfer proteins. Plant J. 1993; 4: 983-91.

Molina A, Garcia-Olmedo F. Enhanced tolerance to bacterial pathogens caused by the transgenic expression of barley lipid transfer protein LTP2. Plant J. 1997;12: 669-75.

Nguyen PH, Zhao BT, Lee JH, Kim YH, Min BS, Woo MH. Isolation of benzoic and cinnamic acid derivatives from the grains of Sorghum bicolor and their inhibition of lipopolysaccharide-induced nitric oxide production in RAW 264.7 cells. Food Chemistry. 2015; 168: 512-19.

Ooi LS, Tian L, Su M, Ho WS, Sun SS, Chung HY, Wong HN, Ooi VE. Isolation, Characterization, Molecular Cloning and Modeling of a New Lipid Transfer Protein With Antiviral and Antiproliferative Activities From Narcissus Tazetta. Peptides. 2008; 29(12):2101-9.

Panikashvili D, Shi JX, Bocobza S, Franke RB, Schreiber L, Aharoni A. The Arabidopsis DSO/ABCG11 transporter affects cutin metabolism in reproductive organs and suberin in roots. Mol. Plant. 2010; 3:56375.

Perrocheau L, Bakan B, Boivin P, Marion D. Stability of Barley and Malt Lipid Transfer Protein 1 (LTP1) Toward Heating and Reducing Agents: Relationships With the Brewing Process. J Agric Food Chem. 2006; $19 ; 54(8): 3108-13$.

Pettus BJ, Bielawski J, Porcelli AM, Reames DL, Johnson KR, Morrow J, Chalfant CE, Obeid LM, Hannun YA. The sphingosine kinase 1/sphingosine-1-phosphate pathway mediates COX-2 induction and PGE2 production in response to TNF-alpha. FASEB J. 2003; 11:1411-21.

Rayaprolu SJ, Hettiarachchy NS, Horax R, Kumar-Phillips G, Liyanage R, Lay J, Chen P. Purification and characterization of a peptide from soybean with cancer cell proliferation inhibition. Journal of Food 
Biochemistry. 2017; 41(4): e12374.

Raychaudhuri B, Fisher CJ, Farver CF, Malur A, Drazba J, Kavuru MS, Thomassen MJ. Interleukin 10 (IL10)-mediated inhibition of inflammatory cytokine production by human alveolar macrophages. Cytokine. 2000;12:1348-55.

Regente MC, Giudici AM, Villalain J, de la Canal L. The cytotoxic properties of a plant lipid transfer protein involve membrane permeabilization of target cells. Lett Appl Microbiol. 2005;40(3):183-9.

Ren J, Zhou W, Wang J. Identifying hierarchical and overlapping protein complexes based on essential protein-protein interactions and "seed-expanding" method. Biomed Res Int. 2014; 2014:838714.

Safi H, Saibi W, Alaoui MM, Hmyene A, Masmoudi K, Hanin M, Brini F. A Wheat Lipid Transfer Protein (TdLTP4) Promotes Tolerance to Abiotic and Biotic Stress in Arabidopsis Thaliana. Plant Physiol Biochem. 2015; 89:64-75.

Sánchez, A.; Vázquez, A. Bioactive peptides: A review. FQS. 2017; 1: 29-46.

Sangtanoo P, Srimongkol P, Saisavoey T, Reamtong O, Karnchanata A. Anti-inflammatory action of two novel peptides derived from peanut worms (Sipunculus nudus) in lipopolysaccharide-induced RAW264.7 macrophages. : Food Funct. 2020;29;11(1):552-560.

Shi Q, Cao J, Fang L, Zhao H, Liu Z, Ran J, Fu J. Geniposide suppresses LPS-induced nitric oxide, PGE2 and inflammatory cytokine by downregulating NF- KB, MAPK and AP-1 signaling pathways in macrophages. International Immunopharmacology. 2014; 20(2): 298-306.

Sun JY, Gaudet DA, Lu ZX, Frick M, Puchalski B, Laroche A. Characterization and antifungal properties of wheat nonspecific lipid transfer proteins. Mol Plant Microbe Interact. 2008; 21(3):346-60.

Tassin S, Broekaert WF, Marion D, Acland DP, Ptak M, Vovelle F, Sodano P. Solution Structure of Ace-AMP1, a Potent Antimicrobial Protein Extracted From Onion Seeds. Structural Analogies With Plant Nonspecific Lipid Transfer Proteins. Biochemistry. 1998; 17;37(11):3623-37.

Tondo EC, Casarin LS, Oliveira AB, Martello L, da Silva Jr EA, Gelli D. Advances in food safety in Brazil(Avanços da segurança de alimentos no Brasil). Vigilância Sanitária em Debate. 2015; 3:122-130.

Tursun X, Zhao YX, Talat Z, Xin XL, Adila T, Abdulla R, AkberAisa H. Anti-inflammatory effect of Rosa rugosa flower extract in lipopolysaccharide-stimulated RAW 264.7 macrophages. Biomol Ther. 2016; 24:184-90.

Van Loon LC, Van Strien EA. The families of pathogenesis-related proteins, their activities, and comparative analysis of PR-1 type proteins. Physiol. mol. Plant Pathol. 1999; 5: 85-97. 
Yang EJ, Yim EY, Song G, Kim GO, Hyun CG. Inhibition of nitric oxide production in lipopolysaccharideactivated RAW264.7 macrophages by Jeju plant extracts. Interdiscip Toxicol. 2009; 2:245-9.

Zottich U, Da Cunha M, Carvalho AO, Dias GB, Silva NC, Santos IS, do Nacimento VV, Miguel EC, Machado OL, Gomes VM. Purification, Biochemical Characterization and Antifungal Activity of a New Lipid Transfer Protein (LTP) From Coffea Canephora Seeds With a-amylase Inhibitor Properties. Biochim Biophys Acta. 2011;1810(4):375-83.

\section{Tables}

Table 1: Growth inhibition zones of (IZ $\mathrm{mm} \pm$ S.E.M), minimal inhibition concentration $(\mathrm{MIC} \mu \mathrm{g} / \mathrm{mL})$ and minimal bactericidal concentration ( $\mathrm{MBC} \mu \mathrm{g} / \mathrm{mL}$ ) showing antibacterial activity for the purified protein TdLTP4 against against foodborne, spoiling bacteria compared to that of positive standard antibiotic (Gentamcin).

\begin{tabular}{|c|c|c|c|c|}
\hline \multirow[b]{2}{*}{ Strains } & \multicolumn{2}{|c|}{$\begin{array}{l}\text { Inhibition zones } \\
\text { diameter }(\mathrm{mm})^{\mathrm{a}}\end{array}$} & \multirow[t]{2}{*}{ MIC } & \multirow[t]{2}{*}{ MBC } \\
\hline & TdLTP4 ${ }^{b}$ & Gentamicin ${ }^{c}$ & & \\
\hline \multicolumn{5}{|l|}{ Bacterial strains } \\
\hline \multicolumn{5}{|l|}{ Gram positive } \\
\hline Bacillus subtilis ATCC 6633 & $26 \pm 1.0$ & $20 \pm 0.2^{\mathrm{a}}$ & $125 \pm 0.4$ & 125 \\
\hline Bacillus cereus ATCC 14579 & $24 \pm 0.0$ & $20 \pm 0.4^{\mathrm{a}}$ & $125 \pm 0.9$ & 125 \\
\hline Staphylococcus aureus ATCC 25923 & $20 \pm 1.0$ & $25 \pm 0.8^{b}$ & $62.5 \pm 0.4$ & 250 \\
\hline Staphylococcus epidermis ATCC 12228 & $16 \pm 0.0$ & $20 \pm 0.5^{b}$ & $250 \pm 0.7$ & 250 \\
\hline Enterococcus faecalis ATCC 29212 & $14 \pm 0.0$ & $12 \pm 0.2^{\mathrm{a}}$ & $250 \pm 0.9$ & 125 \\
\hline Listeria monocytogenes ATCC 19117 & $24 \pm 0.0$ & $15 \pm 0.0^{\mathrm{a}}$ & $62.5 \pm 0.8$ & 62.5 \\
\hline \multicolumn{5}{|l|}{ Gram negative } \\
\hline Salmonella enterica ATCC 43972 & $16 \pm 0.0$ & $18 \pm 0.8^{\mathrm{a}}$ & $250 \pm 0.2$ & 500 \\
\hline Escherichia coli ATCC 25922 & $16 \pm 0.5$ & $21 \pm 1.0^{b}$ & $125 \pm 0.6$ & 500250 \\
\hline Pseudomonas aeruginosa ATCC 9027 & $14 \pm 1.0$ & $18 \pm 0.7^{b}$ & $250 \pm 0.8$ & \\
\hline
\end{tabular}

Values are given as mean \pm SEM of triplicate experiment. 


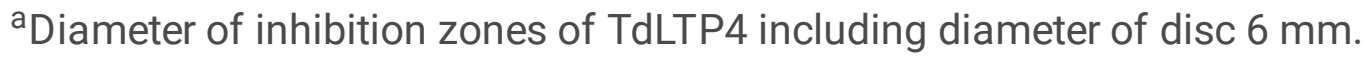

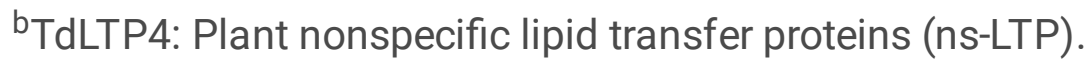

${ }^{\mathrm{C}}$ The used concentration of Gentamicin was $10 \mu \mathrm{g} /$ well.

Table 2: growth inhibition Zones of (IZ mm \pm S.E.M), minimal inhibition concentration ( $\mathrm{MIC} \mu \mathrm{g} / \mathrm{mL})$, minimal fungicidal concentration (MFC $\mu \mathrm{g} / \mathrm{mL}$ ) showing antifungal activity for TdLTP4 against pathogenic fungal.

\begin{tabular}{|llll|}
\hline Fungal strains & I Z (mm) & $\begin{array}{l}\text { MIC } \\
(\mu \mathrm{g} / \mathrm{ml})\end{array}$ & $\begin{array}{l}\text { MFC } \\
(\mu \mathrm{g} / \mathrm{ml})\end{array}$ \\
\hline Aspergillus niger (CTM 10099) & $20 \pm 0.0$ & $125 \pm 0.4$ & 125 \\
Aspergillus flavus (food isolate) & $16 \pm 1.0$ & $250 \pm 0.4$ & 250 \\
Aspergillus nidulans (food isolate) & $18 \pm 0.5$ & $250 \pm 0.6$ & 250 \\
Aspergillus fumigatus (food isolate) & $18 \pm 0.5$ & $500 \pm 1.0$ & 500 \\
Fusarium graminearum (ISPAVE 271) & $22 \pm 0.0$ & $62.5 \pm 0.0$ & 125 \\
\hline Fusarium oxysporum (CTM10402), & $25 \pm 1.0$ & $62.5 \pm 0.5$ & 62.5 \\
\hline Fusarium culmorum (ISPAVE 21w) & $22 \pm 0.5$ & $125 \pm 0.8$ & 250 \\
\hline Alternaria alternata (CTM 10230) & $20 \pm 1.0$ & $250 \pm 0.3$ & 500 \\
\hline
\end{tabular}

Values are given as mean \pm SEM of triplicate experiment.

\section{Figures}




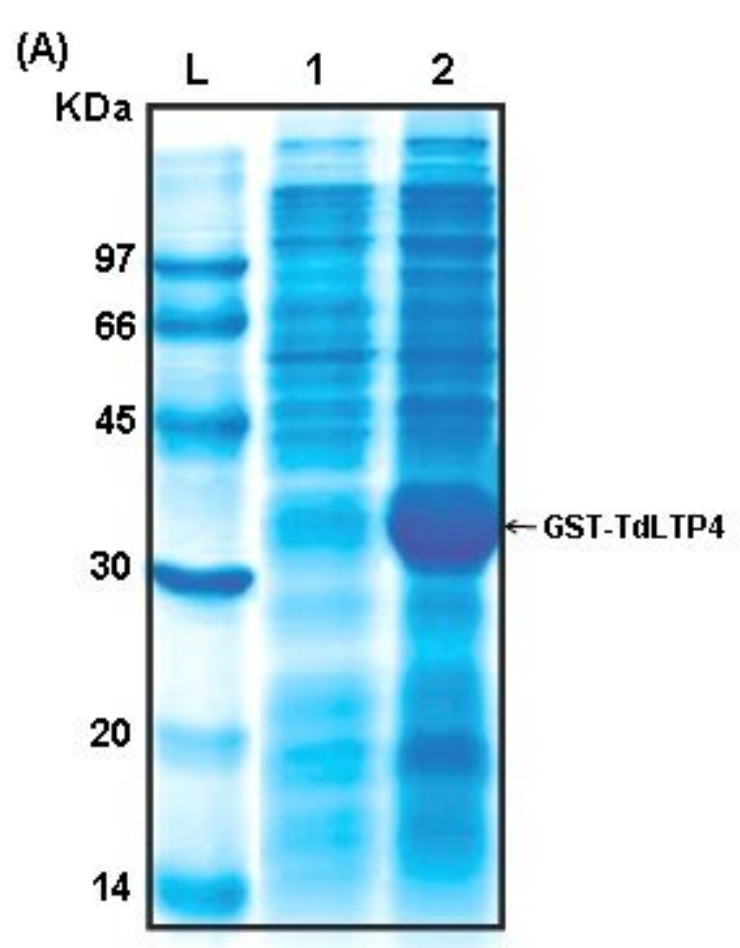

(B)

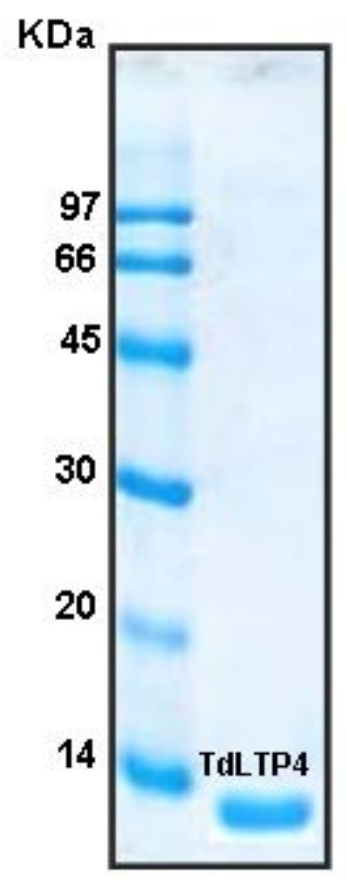

Figure 1

Expression of TdLTP4 protein in E. coli and purification. (A) SDS-PAGE analyses of total proteins extracted from non-induced (lane 1) and GST- TdLTP4 with IPTG induction (lane 2). The arrow indicates the induced GST-TdLTP4 product. (B) The soluble and purified recombinant TdLTP4 proteins after digestion with thrombin. Protein markers are shown on the left panel in $\mathrm{kDa}$. 


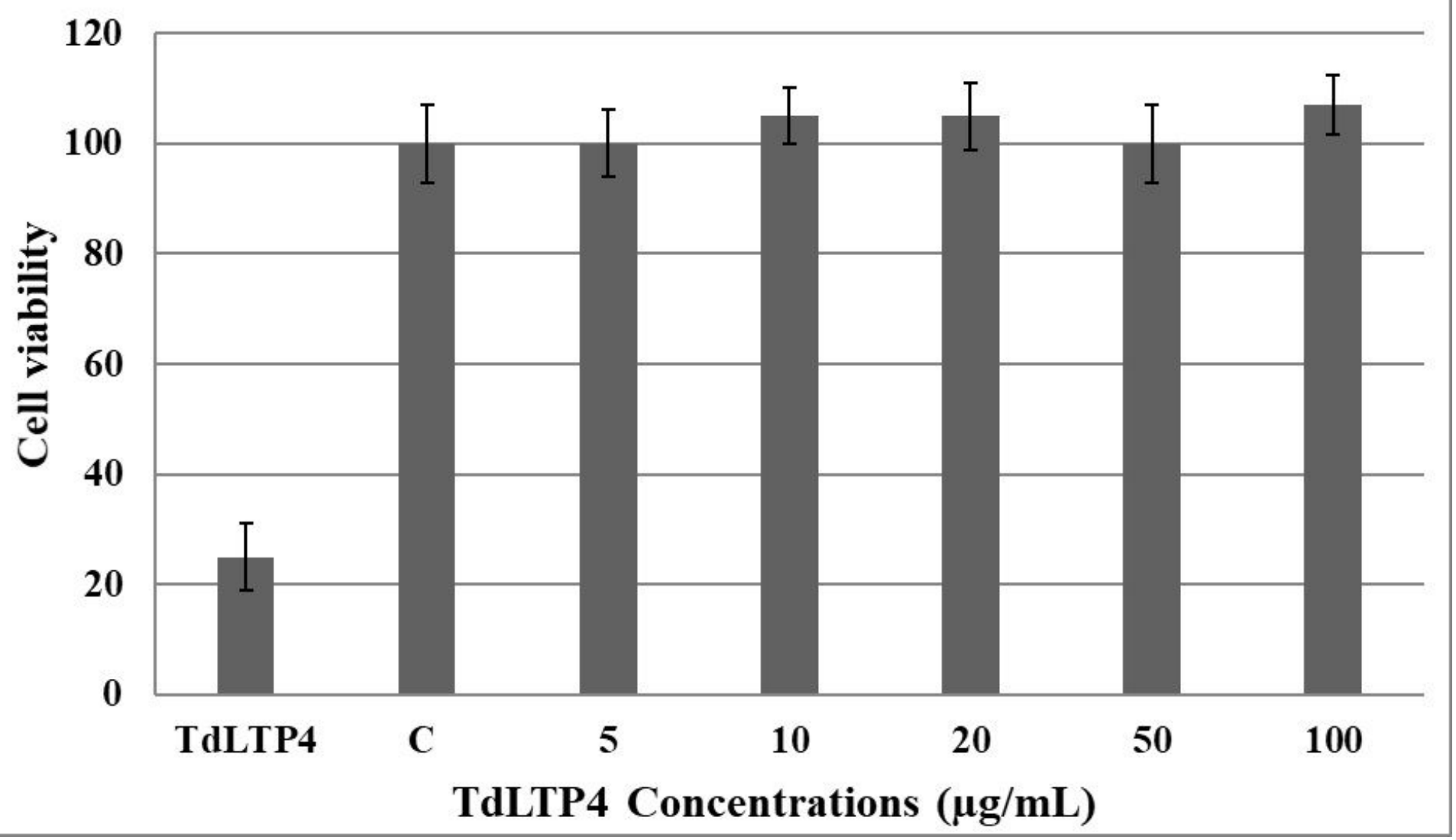

Figure 2

Cytotoxicity of TdLTP4 in RAW 264.7 cells. Cells were treated with different concentrations of TdLTP4 for $24 \mathrm{~h}$, and viability was assayed by the MTT assay. Data represent mean values of triple determinations \pm SEM. TdLTP4 at $100 \mu \mathrm{g} / \mathrm{mL}$ was not cytotoxic. 


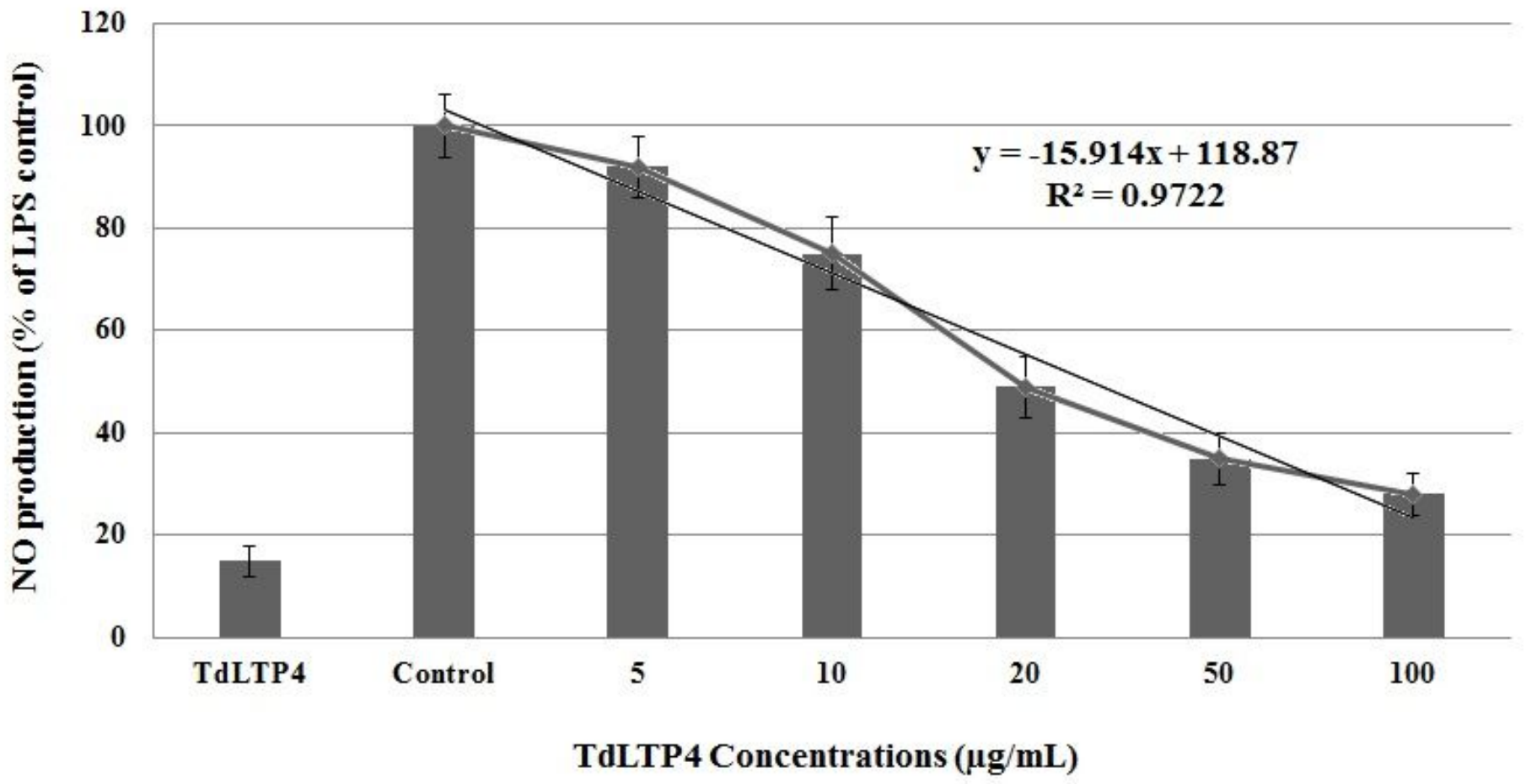

Figure 3

Effect of TdLTP4 on nitric oxide (NO) production by lipopolysaccharide (LPS)-stimulated RAW264.7 macrophages. Cells were incubated in the presence of TdLTP4 or in combination with $0.5 \mu \mathrm{g} / \mathrm{mL}$ LPS for $18 \mathrm{~h}$. The culture supernatant was analyzed for NO by the Griess method. Data are presented as percentages and LPS control (without TdLTP4) was fixed at $100 \%$. Data show mean \pm SEM values of three independent experiments. ${ }^{*} p<0.05$ and ${ }^{* *} p<0.01$ indicate significant differences from LPSstimulation value. $\mathrm{NO}(\mathrm{IC} 50=4.32 \mu \mathrm{g} / \mathrm{mL})$. 

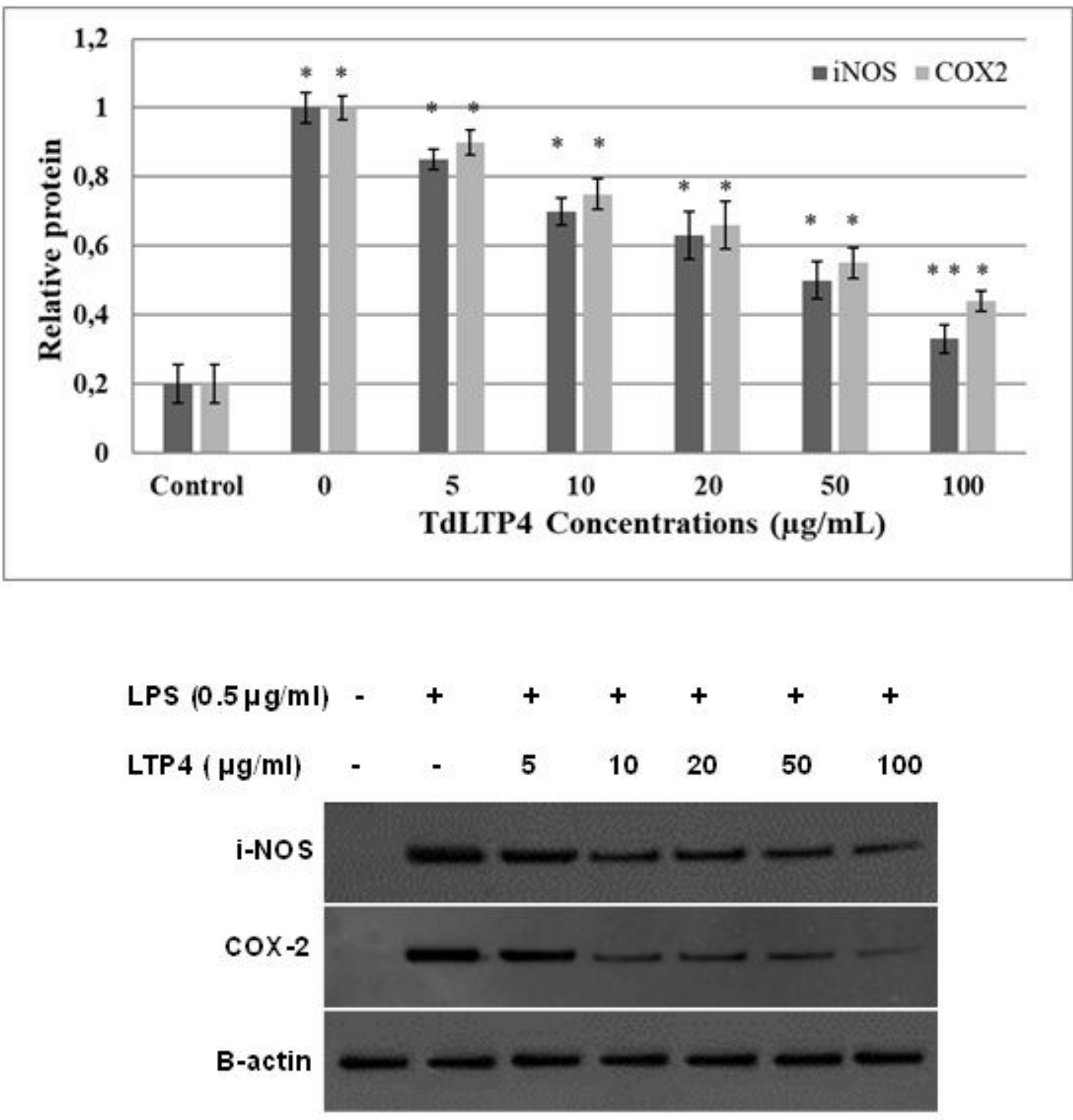

Figure 4

Inhibitory effect of TdLTP4 on protein expression of iNOS and COX-2 in LPS-stimulated RAW 264.7. The results presented are representative of three independent experiments. The iNOS and COX-2 expression levels were determined by Western blotting. Data show mean \pm SEM values of three independent experiments. ${ }^{*} p<0.05$ and ${ }^{*} p<0.01$ indicate significant differences from LPS-stimulation value. 

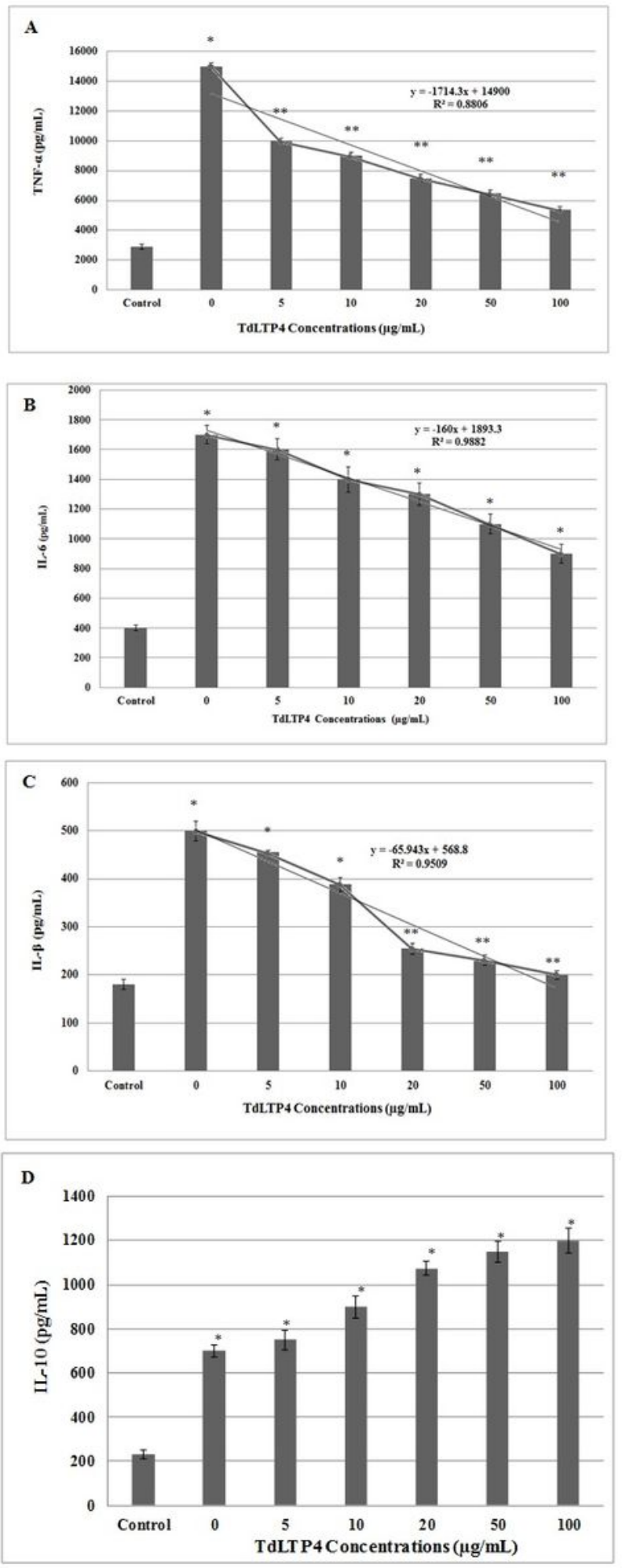

\section{Figure 5}

Effects of TdLTP4 on TNF-a (A), IL-6 (B) IL- $\beta$ (C) and IL-10 (D) in LPS-induced RAW264.7 cells. The cells were pretreated with the different concentrations of TdLTP4 for $1 \mathrm{~h}$ and then exposed to $0.5 \mu \mathrm{g} / \mathrm{mL}$ LPS for $18 \mathrm{~h}$. The levels of TNF-a, IL-6, IL- $\beta$ and IL-10 in the supernatant were determined by ELISA. Data show mean \pm SEM values of three independent experiments. ${ }^{*} p<0.05$ and ${ }^{* \star} p<0.01$ indicate significant 
differences from LPS stimulation value. TNF-a $($ IC50 $=8.66 \mu \mathrm{g} / \mathrm{mL})$, IL-6 (IC50 $=11.52 \mu \mathrm{g} / \mathrm{mL})$ and IL-1 $\beta$ $(\mathrm{IC} 50=7.87 \mu \mathrm{g} / \mathrm{mL})$. 